\title{
Pastoreo extensivo en Un pueblo de Soria: ETNOGRAFÍA DE UN MUNDO EN EXTINCIÓN
}

\section{Extensive Shepherding in a Village of Soria: ETHNOGRAPHY OF AN ENDANGERED WORLD}

\author{
Anna Mata Romeu *
}

Recibido: 04/01/2019 - Aceptado: 06/05/2020

Doi: https://dx.doi.org/10.6018/rmu/356931

Publicado bajo licencia CC BY-SA

\section{Resumen}

El artículo ofrece datos sobre el pastoreo extensivo y sobre los sistemas de cultivo y las formas de vida hasta los años 70 en Torreandaluz, un pueblo del suroeste soriano. Se fundamenta en una etnografía llevada a cabo entre mediados de 2015 y la actualidad. Está basada en la observación participante, la historia de vida de un pastor de Torreandaluz y entrevistas informales a agricultores y pastores jubilados del lugar. Pretende ofrecer una visión sobre el impacto que sobre las formas de agricultura y ganadería ovina extensiva, así como sobre las formas de vida, tuvo la llegada de las técnicas de la llamada Revolución Verde.

\section{Palabras clave}

Pastoreo extensivo, agricultura tradicional, estrategias de subsistencia, bienes comunales, ganadería ovina.

\begin{abstract}
The article offers data on extensive shepherding, cultivation systems and lifestyles up to the 1970s, in Torreandaluz, a village in the southwest of Soria province. It is based on an ethnography carried out from the middle of 2015 until today. The participant observation, the life story of a shepherd of Torreandaluz and informal interviews with farmers and retired shepherds of the place made up this study. It intends to offer a vision about the impact that the arrival of the techniques of the so-called Green Revolution had on agriculture and extensive sheep farming, as well as on forms of life.
\end{abstract}

\section{Key words}

Extensive shepherding, traditional agriculture, subsistence strategies; communal property, sheep farming.

\footnotetext{
Universidad de Lleida. Departamento de Geografía y Sociología.
}

Email: annamata@geosoc.udl.cat 


\section{INTRODUCCIÓN}

El presente trabajo está realizado a partir de la historia de vida de Juan Antonio, un pastor nacido en 1940 en Torreandaluz, pueblo situado a 975 metros de altitud en el suroeste de Soria. Es una entidad local menor perteneciente al municipio de Valderrodilla. Según el INE contaba en 2016 con 33 habitantes de derecho, aunque en realidad los que viven habitualmente no llegan a la decena.

La etnografía que de forma reducida presentamos refiere una época en la que la gente sobrevivía trabajando la tierra de forma extensiva, aprovechando recursos del ganado, principalmente ovino, en una economía de subsistencia adaptada al medio, que empleaba la fuerza de las gentes y de los animales y que destinaba una parte importante de la producción a satisfacer sus necesidades básicas; dejando otra parte, oscilante año a año, para vender en el mercado, lo que les permitía comprar productos que no producían, y un pequeño ahorro que quizás les protegiera de un futuro incierto.

Se escogió la historia de vida de Juan Antonio porque fue uno de los últimos pastores en Torreandaluz; por su capacidad de recuerdo; por haber vivido la transición a un nuevo tipo de agricultura y ganadería, y porque su vida ha transcurrido acoplada a la naturaleza respetando sus recursos, animales y plantas, aprendiendo del contacto y el respeto al medio que le ha tocado vivir, consciente de que hay que colaborar respetando el entorno para que este no se agote, más bien mejore, y permita sobrevivir a nuevas generaciones.

Pocos años estuvo en la escuela, su familia, necesitada de su trabajo, tuvo que decidirse para que la abandonara en su niñez, eran las privaciones de la época. El campo se convirtió en su aula pese a su corta edad. Pero aun así, él ha aprendido muchas cosas a lo largo de la vida, de las personas, de los animales y de las plantas que le han rodeado. Aprendizaje basado principalmente en la observación, incorporando conocimientos de sus vecinos gracias a la experimentación y a la transmisión oral, que permite acopiar y contrastar las experiencias de tantas otras gentes que le precedieron:

\footnotetext{
"Cuando tenías nueve o diez años te metían a guardar. Aunque en general era de los once a doce años. El padre se dedicaba a la tierra y también ayudaba a los chavalejos, puesto que éramos muy pequeños, pastores y pastoras, también ellas participaban, daba igual. Las chicas iban a guardar como los chicos, lo que había en cada casa. Se empezaba a hacer de pastor ya con nueve años. Yo empecé con las paridas en invierno, con nueve años. Era tan pequeño que un señor fue a decir a mi padre que las ovejas estaban solas en el campo, porque a mí no se me veía entre ellas, y fueron a ver qué pasaba, pues dijeron "a este le ha pasado algo", y estaba allí entre
} 
las ovejas. (...) Al principio guardabas las parideras. Luego en primavera se juntaban todas, y si el más pequeño no podía iba un hermano mayor. Había para todos, el que no iba todos los días a las ovejas pues iba a escardar, a las guijas o a lo que fuera» (Juan Antonio).

Su vida es la historia de un pastor que desde los nueve años hasta su jubilación se ha visto rodeado de ovejas, corderos, moruecos, perros, y que ha hecho largos recorridos, hiciera calor, frío o cayeran tormentas, entre las tainas y campos de Torreandaluz. Siguiendo horarios y ritmos estacionales, combinando el rebaño con el cultivo de la tierra y desde los años setenta ampliando el hatajo de ovejas y sustituyendo los mulos por el tractor. Toda una historia digna de ser rememorada, aunque nos centraremos principalmente en las formas de producción que abarcan desde su niñez hasta principios de los años setenta del pasado siglo.

\section{OBJETIVOS}

Con el presente trabajo pretendemos reconstruir las formas de vida de la época que abarca desde 1940 hasta la década de los setenta, cuando el modelo de agricultura tradicional y pastoreo de ganadería ovina estante cambian hacia prácticas y modos de subsistencia de la agricultura de la denominada Revolución Verde.

Pretendemos reproducir un modelo de agricultura y pastoreo tradicional y recoger las particularidades de ese modo de vida, para que no caigan en la amnesia y que cuando todas aquellas gentes que vivieron dicha época desaparezcan, se conserve algo vivo en la memoria de las nuevas generaciones, que vean en estos conocimientos un museo vivo, que les sirva de contraste para ensanchar su forma de ver el mundo.

La etnografía realizada en Torreandaluz pretende ir más allá de las vivencias de un pastor en concreto, Juan Antonio, y, aunque se basa principalmente en su historia de vida particular, aspira a ilustrar las formas de vida de sus convecinos y de otros pueblos de la zona con similares condiciones. ${ }^{1}$

La transformación que ha sufrido Torreandaluz puede ilustrar y caracterizar lo sucedido en muchos pueblos de Castilla e incluso otras áreas, una

\footnotetext{
1 V. como ejemplo La Ventosa de Fuente Pinilla (Vallejo, 2009) o, más genérico, diferentes pueblos de Soria en Goig (2015).
} 
transformación irreversible, puesto que el modelo de ganadería anterior a la Revolución Verde es imposible de reproducir con las estructuras agrarias actuales.

\section{METODOLOGÍA}

En 2014 emprendimos un estudio etnográfico en Torreandaluz, tras constatar que Juan Antonio había conservado unos cien instrumentos usados en el campo, en los corrales y en las casas, la mayoría de los cuales ya no se utilizaban, pero que él, a su manera, los tenía organizados y los enseñaba a todo el mundo que mostraba interés.

En 2014 fotografiamos dichos instrumentos y hasta finales de 2015 realizamos una exhaustiva ficha para cada uno de ellos en la cual recogíamos el nombre del instrumento, el nombre de cada una de las partes del mismo, los materiales en que estaba construido y las formas en que era utilizado.

Para realizar las fichas sobre los instrumentos, se realizaron largas entrevistas semiestructuradas a Juan Antonio sobre las formas de cultivo y de pastoreo antes de los años sesenta, y se hicieron otras de informales con otras personas que habían sido agricultores o pastores en el pueblo. De este conjunto de informaciones y de las aportaciones bibliográficas surgió el guion para las entrevistas dirigidas a reconstruir la historia de vida.

Desde finales de 2014 hasta 2016 realizamos un exhaustivo estudio bibliográfico, centrado en los bienes y aprovechamientos comunales, los modos de producción agrícola y de pastoreo tradicionales, los cambios experimentados por dichos modos entre 1950 y 1970 y la consiguiente despoblación del medio rural fruto de la crisis del sistema agrario tradicional.

La historia de vida de Juan Antonio fue recogida mediante entrevistas en profundidad a lo largo de 2016 y 2017, y se fue construyendo progresivamente intentando seguir el nudo de los cambios experimentados en sus experiencias de pastor.

El análisis que sigue se fundamenta en la etnografía sobre el pastoreo y en la aproximación bibliográfica al pastoreo y la agricultura antes de los años 60 del siglo pasado, centrada en las tierras de Castilla y de Soria. El tema de los bienes comunes y propios también es abordado, puesto que tienen una influencia muy importante en la vida rural. Y por último se analiza el impacto que tuvo en los pueblos la mecanización y el paulatino desaparecer de las ovejas. 


\section{LA IMPORTANCIA DEL PASTOREO EN LAS TIERRAS DE SORIA}

Los 975 metros de altitud sobre el nivel del mar de Torreandaluz así como las circunstancias orográficas, edafológicas y climatológicas han supuesto un condicionante importante para la modalidad de agricultura y ganadería que se podía realizar en dicho lugar. Son tierras que producen pastos cortos y pobres, escasos en verano, aunque apropiados para su utilización por el ganado ovino. Ecológicamente esta forma de pastoreo suponía una adaptación satisfactoria puesto que se utilizaban pastos que no podían usarse sino por el ganado ovino in situ, así como otros recursos agrícolas residuales difícilmente aprovechables de otro modo.

Bachiller (1996), refiriéndose al suroeste soriano, dice que la zona tiene unas condiciones más favorables para la ganadería lanar que para la agricultura (clima árido, inviernos fríos, suelos pobres y pastizales de baja productividad); así, estos animales aprovechan los espacios más marginales, ya que los ovinos son de los ganados más sobrios y resistentes a las oscilaciones del clima, y con menor exigencia en cuanto a cuidados y calidad de la alimentación. Están adaptados a pastos y alimentos secos, ásperos, ricos en fibra, así como a rastrojos y restos de la recolección:

«Yo las tenía muy enseñadas a las ovejas y trabajaba mucho con el ganado, pues las tenía enseñadas a que no se comieran los frutos que no se tenían que comer. Pero hay que conocerlas mucho» (Juan Antonio).

El modelo de pastoreo era extensivo, y aprovechaba los pastos que se dan en los montes bajos, en sierras y eriales, así como las rastrojeras de cereal y las hierbas de los barbechos. En invierno el ganado era alimentado con despojos procedentes de la paja de los cultivos de cereales y con forrajes sembrados adrede, cortados en primavera en las fincas agrícolas de los productores y almacenados para su consumo en las tainas del pueblo:

«Pues aprovechábamos los pastos del monte, de los ciratos ${ }^{2}$ y de los arroyos, pero sobre todo de los barbechos y rastrojeras. En verano los pastos se agostaban, pero teníamos los barbechos y las rastrojeras. Siempre teníamos forraje propio, pues como luego venía el invierno, pues almacenabas para el invierno, bastante, te sobraba y todo por miedo a que viniera un invierno malo. Pues si tenías que comprarles te veías mal para salvarte. Llegaba el invierno y el pasto desaparecía, y te podía caer una nevada que estuvieras veinte días sin poder salir al campo. Cuando nevaba solo

2 En Torreandaluz se refiere a los espacios o franjas de tierra que separan dos parcelas. 
salían para beber agua, estaban cerradas. (...) En el barbecho comían y preferían ababoles y mielgas y algunas hierbas que han desaparecido con los herbicidas. En los yermos variaba la comida de un metro cuadrado a otro. No todas las hierbas son igual de buenas, pero la oveja cuando tiene, lo primero que se come es lo bueno, y lo otro cuando no hay de lo bueno. Los rastrojos, si no criaban, las iba manteniendo, cuando se segaba a mano quedaba mucho grano, luego con las cosechadoras no tanto, y ya comían paja, y retoño en septiembre» (Juan Antonio).

Todos estos aprovechamientos se pierden en la actualidad, puesto que no son utilizados de ninguna forma (en buena parte se eliminan con herbicidas), no obstante, contradictoriamente, mantenemos cabañas ganaderas intensivas estabuladas, que requieren de forrajes y de alimentos que han sido producidos intensivamente y con un alto coste energético y ecológico:

"Y ahora entre tractores y herbicidas no hay tanta comida. El herbicida ha hecho mucho daño, se empezó a echar herbicida con los mulos, con una máquina, hace cuarenta y cinco años. Después ha ido aumentando el uso, ahora se echa antes de labrar, después de sembrar y cuando sea. Ha hecho muchos daños a los pastos» (Juan Antonio).

Es evidente que las prácticas de pastoreo han influido en procesos ecológicos, económicos, sociales y culturales que vinculan a la ganadería extensiva con el territorio, sus gentes y sus actividades de toda índole. La biodiversidad resultante alcanza mayores cuotas de complejidad que las prácticas intensivas que hoy en día las sustituyen. Sin olvidar la capacidad desbrozadora del ganado, tanto en los montes y bosques como en las parcelas cultivadas, que contribuía a un paisaje concreto que en la actualidad se está modificando. También debe tenerse en cuenta su aportación a la prevención de incendios, así como el aprovechamiento de residuos agrícolas inservibles de otra manera. No obstante, dificulta el crecimiento de los brotes tiernos y plántulas de las zonas arbóreas, contrastado porque en zonas que han abandonado el pastoreo se produce mayor crecimiento de encinas, robles, enebros, etcétera:

«Fíjate como está cambiando el paisaje desde que no tenemos ovejas. Crecen carrascas, enebros y otro tipo de plantas» (Juan Antonio).

El pastoreo tiene una gran importancia, no solo porque elimina y aprovecha masa de pastos naturales y pajas de cereales sino porque las ovejas sirven para dispersar semillas de pastos y plantas (Manzano, 2004), lo que asegura su constante reproducción en el área de pastoreo. El transporte lo realizan depositando las semillas que comen unos días antes, tras haberlas rumia- 
do, y transportando semillas entre sus lanas (propágulos adheridos) que van depositando escalonadamente. Tanto las semillas que comen como las que se les adhieren, debido al pastoreo diario, están en constante movilización y cruce de unos espacios a otros.

El pastoreo también contribuye a favorecer y facilitar la aparición de la seta de cardo corredor, puesto que comen los pastos de los campos, dejando la hierba rasa lo cual ayuda al crecimiento de esta seta tan apreciada en la zona, incluso por las mismas ovejas:

«Si no tenían mucha hambre las hierbas peligrosas no las comían, como con las setas, alguna se moría alguna vez, porque comían setas venenosas, pero por entrar con mucha ansia y comerse las setas sin olerlas, y han llegado a morir, pero las huelen y suelen apartarse de ellas. No ha pasado muchas veces, sino llevan hambre las huelen y las dejan, a veces pueden mascarla y dejarla, si no tienen hambre las dejan. Les gustan mucho las setas» (Juan Antonio).

El pastoreo extensivo es fundamental para mantener buenas condiciones ecológicas en los pastizales y sus ecosistemas, y para producir carne sin necesidad de utilizar productos agrícolas y, por tanto, enormes cantidades de agua. La gran biodiversidad de especies de la Península Ibérica se debe, en parte, a las prácticas de pastoreo y especialmente a la trashumancia, sin olvidar que mejoran la estructura del suelo y su productividad (Garzón, 2012):

«Se sacaba la basura (o estiércol) una vez al año, y se llevaba a la finca, se dejaba en
montones. Luego se esparramaba con la horca o pala, y se daba una labor y si la tie-
rra estaba bien, se sembraba ya. Se le daban vueltas a la basura de los mulos en el
muladar. Dos o tres vueltas para que se repudriera, según, si estaba seca, algunos la
mojaban. Estaba un año o más en el estercolero. Se hacían varios estercoleros.
Algunos seguían las lunas para removerlo. Se notaba las tierras que se estercolaban»
(Juan Antonio).

Tomando como referencia el estudio de Bachiller (1996) sobre el suroeste soriano y ante la ausencia de datos específicos sobre Torreandaluz, podemos inferir que ha seguido el parámetro de los pueblos del suroeste de la provincia, que hasta los años 50-60 del pasado siglo mantuvieron la actividad agraria tradicional: sin inputs externos y con pequeñas explotaciones familiares dirigidas al autoconsumo: minifundio. La mayoría de agricultores cultivaban tierras de propiedad, en las que predominaba el barbecho; luego el trigo, la cebada, avena y centeno, por el sistema de cultivo extensivo de año y vez. El barbecho suponía el 50\% de la superficie cultivada. Las pequeñas explotaciones familiares completaban sus rentas y dieta alimenticia con actividades 
ganaderas, la ovina era la más adaptada a las condiciones topográficas y climáticas y la que mejor combinaba con los cultivos de secano; disponían también de cerdas y cerdos de engorde, gallinas, varias vacas o mulas y algunas palomas. Como plantea Bachiller, la mitad de las explotaciones agrícolas «disponían de un rebaño, generalmente inferior a las 100 cabezas» $(1996,120)$ del que obtenían algunos ingresos:

"Antes éramos autosuficientes. Comprábamos ropa, calzado, alguna vez algún mueble, aceite y vino. Teníamos gallinas, cerdos, cabra para leche o vaca, patatas, lentejas; y fruta, y de eso no comprabas. Fruta no comías cada día como ahora. (...) Tener entre sesenta y ochenta ovejas parideras entonces ya era un buen rebaño. Había que tenían pocas y en primavera y veranos las arrebañaban, pero los menos» (Juan Antonio).

Esto fue viable hasta la mitad del siglo XX. Luego vino la mecanización y la roturación de nuevas tierras a costa de tierras de pastos. No solo sucedió en esta comarca, puesto que, como relata Bachiller (1996), entre 1962 y 1982 la superficie cultivada creció en 95.492 hectáreas en la provincia de Soria:

\footnotetext{
"Cuando llegaron los tractores fueron disminuyendo los ganaderos. A muchos se les fueron los hijos y tuvieron que quitar las ovejas, pues no había quien las guardara. Se fue mucha gente, y se sacaron los ganados. Entre los años 60 y los 70 se despobló de gente y de ovejas. Quedaron cuatro rebaños, y de las ochenta ovejas por rebaño se pasó a cuatrocientas o quinientas. Los tractores hicieron que quedara la mitad de barbecho de lo que quedaba anteriormente. Era un perjuicio fuerte, y se labraron tierras liegas y yermos, excepto lo que no se podía ya labrar. Y la gente hacia lo que le parecía» (Juan Antonio).
}

Según datos de la Diputación de Soria, durante los 30 años que abarcan desde los años 70 hasta finales del siglo XX se observan profundos cambios en el sector ganadero de la provincia, con incrementos importantes del ganado porcino y descensos del lanar, cabrío, vacuno, caballar, mular y asnal. Especifican como causas del descenso del ganado ovino: la fuerte emigración de la población activa agraria; la política agraria de protección al cultivo del trigo; la pérdida de superficies susceptibles de pastar; el excesivo grado de mecanización; la desfasada legislación sobre pastos, hierbas y rastrojeras; la evolución de la demanda de productos de origen animal; los defectuosos canales de comercialización; la falta de modernización de las explotaciones que impiden la aplicación de nuevas técnicas de producción, sin olvidar la dificultad de encontrar pastor: 
«Antes el oficio de pastor era bien visto, sobre todo si cogías fama, porque la gente sabía quién era buen pastor. Antes había mucha gente que tenía interés en tener buen ganado y en hacerlo bien, ahora nada, te odian. Además, ahora casi no hay. Antes también pasaba que había gente que no le gustaba nada, que estaban deseando que les llegara el relevo de su hermano o hermana. Algunos les gustaba, pero no han salido muchos. Mira cuántos han quedado. Muchos han ido a las ovejas, pero odiándolas, solo hace falta oír lo que decían o dicen de las ovejas, hablando mal todo el tiempo de ellas. Muchos tenían que ir porque a la familia le interesaba para poder salir adelante, y esos las odiaban. Por eso tampoco no aprendían» (Juan Antonio).

Según el INE (2016) la provincia de Soria es la menos poblada de España. Atendiendo a la densidad de población es uno de los territorios más despoblados de la UE $(8,74$ habitantes/Km²). Martínez $(2014,398)$ afirma que tiene la más alta tasa de envejecimiento de la UE, y 94 de sus 183 municipios tienen menos de 100 habitantes. El municipio de Valderrodilla cuenta con 77 habitantes (según Padrón de 2016). Este es el panorama en el que nos situamos y Torreandaluz es un claro exponente de esta realidad demográfica y social.

\section{LAS TIERRAS COMUNALES}

Dotar de carácter comunal una parte importante de las tierras y recursos supuso una estrategia para repoblar los campos castellanos que se iban conquistando a los musulmanes, y como bien han planteado distintos autores (Pérez, 1993) eran formas pensadas para una economía escasamente monetizada y de autoconsumo.

Es suficientemente conocido que el sistema de bienes comunales, paralelo al de la pequeña propiedad, condicionó, desde la Reconquista, la estructura económica y organizativa de muchos pueblos castellanos; haciendo posible una ganadería ovina extensiva, que convivía con el cultivo por cada grupo familiar de parcelas para autoabastecerse (personas y animales) pudiendo generar, además, un pequeño excedente que se vendía en el mercado comarcal.

Este sistema comunal permitió la explotación de todos los recursos productivos (montes, dehesas, baldíos, tierras cultivables) y la adecuación de las parcelas particulares a un sistema de cultivo de cereales, leguminosas y forrajes, acorde con una ganadería ovina extensiva. Esta requería poder utilizar de forma común tanto los bienes comunales como los particulares, regulando colectivamente el acceso a dichos recursos en determinadas épocas del año, 
restringiéndolo en otras para permitir la recuperación biológica de los pastos y otros recursos. Era un ejemplo de gestión ecológica por parte del común de los vecinos de los recursos, en función de las características de los terrenos y de las condiciones estacionales, asociadas a factores climáticos.

Esta idiosincrasia de los bienes comunales, así como su interrelación con las parcelas particulares, ha sido analizada y criticada desde distintas perspectivas. A veces se habla de sobreexplotación, otras de las dificultades para su utilización, debido a su naturaleza colectiva. Es conocido el planteamiento de Hardin cuando en 1968 escribe "The Tragedy of the Commons", y plantea que los recursos comunes solo tienen justificación si es en condiciones de baja densidad de población, puesto que para Hardin si existen comunes, no hay control sobre la procreación y reproducción sin restricciones. Pone el ejemplo del pasto abierto en el que cada pastor intentará poner el mayor número de cabezas de ganado. Si existe baja densidad de población no habrá problemas, pero si aumenta la densidad se puede convertir en tragedia por agotamiento de los recursos comunales.

A pesar de la crítica de Hardin a los comunes, existen numerosas referencias de que en toda Europa se han dado y se dan ejemplos de gestión exitosa de los pastos, partiendo de la administración racional de los que los utilizan. Martínez Veiga $(1993,102)$ plantea que muchas de las ordenanzas que se conocen de los pueblos de León reproducen el modelo europeo de gestión de las tierras comunales, regulando el número de cabezas de ganado que cada vecino podía llevar a las tierras comunales y el período estacional en que podían hacerlo:

«En la dehesa se podía entrar todo el año hasta que se agostaba, y excepto de marzo o abril a mayo que se acotaba, y en san Isidro se podía volver a entrar, en ese tiempo se regaba, y ya no se dejaba pisar al ganado. Así se repoblaba. "Echaban al verde", que se decía en san Isidro. En verano estaba el ganado mayor y no se podía regar porque pisaban y era malo, o bien ya no había agua. En la dehesa guardaban el vaquero y el cabrero. También había habido porquero, pues reunían todos los cerdos en la dehesa. Los vaqueros y cabreros, no tenían tierra propia, por eso hacían esta función. Luego, cuando desaparecieron, se hacía por turnos, por adra» (Juan Antonio)

Como ha descrito Blanco (2014), en tierras castellanas durante toda la Reconquista, especialmente en el valle del Duero, las tierras conquistadas a los musulmanes, fueron asignadas a los colonos, en muchos casos bajo formas comunales como indicaban Las Partidas, que suponían la atribución conjunta, mediante fueros y cartas, de tierras para los repobladores. Los bienes comunales eran de distintos tipos: ejidos, dehesas, baldíos y montes. 
Siguiendo a Blanco (2014), las dehesas permitieron distintos usos: agrícolas, ganaderos y forestales. De su importancia da fe que las dehesas boyales (para el pasto del ganado de labor) fueron exceptuadas de la desamortización (Ley 11 de julio de 1856). Los baldíos, generalmente terrenos incultos y de escasa calidad, eran utilizados por la comunidad vecinal del municipio donde se ubicaban. Los montes eran aprovechados comunalmente para leña, madera y pastoreo:

«Las tierras comunes se repartían para sembrar los agricultores que había, si son doscientas hectáreas, lo que tocaba en suerte era para seis años y al otro turno te tocaba otra. En el monte para leña, aquí no puedes cortar, pero no se hacen suertes. La gente compramos suertes en la Muela, ahora pides cortar leña y los guardas te mandan dónde cortar aunque no sea en lo tuyo, ${ }^{3}$ pues ahora en sí no sabes dónde las tienes» (Juan Antonio).

El estado de los bienes comunales ha sufrido distintas vicisitudes, dependiendo del momento histórico, y de la importancia económica de dichos bienes, y, exceptuando las dehesas, cuando aumentaba la población y las cargas tributarias, podían ser «usurpados» y trabajados por los agricultores de los concejos (Blanco, 2014, 11):

\footnotetext{
«Con el tractor se empezó a roturar tierras que antes no se trabajaban. Tanto de particulares como de los comunales. Por ejemplo, se roturaron sesenta hectáreas cuando llegó la luz, en 1956, y así el Ayuntamiento, con las rentas, pagó menos. También se roturaron tierras del Ayuntamiento cuando se puso el agua y se hicieron las calles, así el Ayuntamiento, con las rentas, tenía dinero para pagar el cemento y otras cosas. Entonces no había tanto dinero y las faenas se hacían a hacenderas» (Juan Antonio).
}

Pérez Romero (1995) habla de patrimonios comunales o bienes concejiles para incluir los bienes comunales y los propios. Sin entrar a fondo en la distinción y evolución de este tipo de acceso y propiedad al patrimonio común de los vecinos de un lugar, debemos señalar que, siguiendo a Pérez (1993) y Serna (1993), desde la Recepción del Derecho común del siglo XIII empieza a moldearse la figura del municipio como entidad con personalidad propia y separada de los vecinos, y se suceden los intentos de pasar la propiedad comunal del común de los vecinos al municipio; quedando en muchos

3 Se refiere a que en 2017 la leña que piden cortar se les proporciona según los criterios de los guardas forestales, que no siguen la pauta de priorizar la suerte de quien les demanda la leña. 
lugares el derecho de aprovechamiento en manos del común de los vecinos y la titularidad del municipio:

\begin{abstract}
«Antes había Concejo de vecinos, pero ahora ya no se hace. Nos reuníamos y se tomaban acuerdos. Había el Ayuntamiento, la Cámara y el Concejo. Pero lo del Concejo se terminó, éramos muy pocos. (...) Ahora no se hacen hacenderas, van a trabajar y el Ayuntamiento les paga algo, cuando ya no había gente pues se terminaron las hacenderas, como que los cinco vecinos agricultores llevan cuarenta hectáreas del común cada uno y pagan menos por hectárea al Ayuntamiento, a cambio de pagar menos hacen algunos trabajos. Cuando te jubilas dejas de ir a hacenderas y dejas las tierras del común. En la dehesa hacen los trabajos entre los cinco agricultores y lo que sale para el Ayuntamiento. Los cinco vecinos están empadronados pero se van a Soria a la noche» (Juan Antonio).
\end{abstract}

Desde 1254 en Las Partidas ya se diferenciaba entre «bienes de propios» y «bienes comunales». Siguiendo a Serna (1993), los bienes de propios, aunque son bienes comunales, no son utilizados directamente por los vecinos de forma gratuita; los concejos administran sus rentas y frutos pero no pueden enajenarlos, ni darlos a empeño, ni en censo. Se explotan bien por explotación directa de los vecinos a cambio de una renta, o se arrendan a particulares.

Después de resistir los intentos de cargar de impuestos o de privatizar los bienes comunales por parte de los Austrias, pero sobre todo de los Borbones, así como de las sucesivas desamortizaciones, parte de ellos, los que no pasaron a dominio particular, han llegado como un patrimonio comunal hasta nuestros días, y persisten formas de gestión de vecinos y municipales, siendo definidos en el Reglamento de Bienes de las Entidades Locales de 1986 (Pérez 1993, 156).

La realidad productiva de la agricultura moderna dirigida al mercado contrasta con el modelo de bienes comunales más propios de un modelo de autoconsumo, que garantizaba un mínimo de subsistencia para los más pobres Martínez $(2014,16)$, por lo que este tipo de bienes no se ajusta a las prácticas agrícolas actuales.

En Tierra de Soria, siguiendo a Pérez Romero (1995), el cual se basa en el catastro de Ensenada, las tierras concejiles eran el $72 \%$ de toda la superficie. Montes y dehesas constituían el $81,95 \%$ de las tierras concejiles. La gran cantidad de tierras concejiles se contrarrestaba por su baja calidad: casi la mitad baldíos y apenas comprendían tierras de cultivo. Las tierras comunales tenían una amplia versatilidad funcional, aunque dehesas y montes concejiles servían para obtener la energía mecánica (alimentación para el ganado de labranza y de transporte) y calorífica imprescindible para las explotaciones 
campesinas. Los baldíos, aunque algunos eran roturables, por su baja calidad del suelo y ubicación excéntrica tenían una dedicación básicamente ganadera (muy especialmente como veranaderos de los rebaños trashumantes). Las dehesas boyales alimentaban el ganado de labor, aunque también se podían dedicar al ganado mayor destinado a producir carne, y ocasionalmente se abrían al ganado menor; algunas podían arrendarse como agostadero de los rebaños trashumantes. Sólo el 59\% de las hectáreas de la Tierra de Soria se consideraban productivas, el resto se consideraban yermas. De las productivas, sólo el 40\% eran cultivadas a mediados del siglo XVIII (huertos o sembraduras). El resto de la superficie productiva eran montes (26\%), dehesas (8\%), prados y eras. Los cultivos se basaban en el cultivo rotativo, de año y vez (sólo un 1,5\% en las vegas se cultivaba anualmente), de cereales (trigo, cebada, avena y centeno), combinado con leguminosas en corta cantidad (lentejas, guijas, arvejones o yeros). El centeno sólo o combinado con avena y cebada era mayoritario. Los árboles frutales eran escasos y la vid de cierta importancia hasta el siglo XVI, hacía más de un siglo que había desaparecido. Los rendimientos eran bajos:

\footnotetext{
«Los corros más malos eran para centeno, luego la avena, trigo y cebada. La avena también en malo. Para forraje se hacían mezclas: veza con avena. La veza para que no se cayera la avena. También se hacía alfalfa y esparceta. Se hacían dos cortes de alfalfa y esparceta, y estaban en la tierra cinco o seis años, luego salía hierba y se había de cambiar. Se hacían en secano, en tierras frescas, sin regar» (Juan Antonio).
}

Pérez Romero (1995) recoge que la sentencia de Chinchilla ampara en una Real Carta Ejecutoria de 1685 el principio de la comunidad de pastos, según el cual todos los bienes concejiles, y las tierras particulares, cortado el heno y alzado el fruto son pasto común de la Ciudad y Tierra de Soria, por lo que todos los vecinos "podían introducir sus ganados de forma permanente, libre, gratuita y sin limitaciones numéricas" (Pérez Romero, 1995, 188). También se incluyeron a partir de varias sentencias los despoblados, rastrojeras y barbechos, una vez levantada la cosecha:

\footnotetext{
"Cuando se segaban los campos se seguían los rastrojos con las ovejas. Hasta que no se veía que el $90 \%$ de la mies estaba en la era, los rastrojos estaban vedados, no se podía entrar. Luego un día se decía "se han desvedado los rastrojos" y ya se podía entrar. Además había un coto, en toda la mejor tierra se dejaba un trozo para el ganado mayor y se hacía murecada, que se podían poner también los moruecos (localmente se dice murecos). En principio había una persona que los guardaba, cuando disminuyeron los ganaderos se hacía por adra» (Juan Antonio).
} 
Pero las desamortizaciones, más la de Madoz que la de Mendizabal, siguiendo a este autor, tensionaron a los ganaderos que querían acceder a los pastos comunales y rastrojos, con los agricultores que querían acotar e impedir el acceso a sus tierras particulares, lo que favoreció una política que fomentó la "particularización de los aprovechamientos y concluyó con la privatización de los bienes de propios y muchos comunales» (Pérez Romero, 1995, 360).

A pesar de los ataques a los bienes comunales, estos han generado un tipo de aprovechamientos que socialmente beneficiaban a agricultores con pequeñas propiedades y, como bien ha planteado Mato (2010), desde tiempo inmemorial importantes extensiones de tierra se utilizaran colectivamente para pasto y monte, posibilitando un «recurso común indiviso» al servicio de todos los vecinos:

«El Ayuntamiento cobraba de la dehesa, que era comunal, del común de los vecinos, y luego cobraba de los cerros y de los liegos, según las hectáreas a los ganaderos, por usar los pastos. Eso se pagaba como a los que tenían fincas, pero el Ayuntamiento tenía más y por tanto cobraba más. Entonces se prorrateaba entre los ganaderos, por el ganado mayor y por las ovejas. Las crías de ovejas no pagaban, los moruecos como una oveja. El ganado hasta que no tenía un año no pagaba pastos, porque antes el cordero se llevaba todo el tiempo a pastar con el ganado, desde que nacía hasta que se vendía, por eso el cordero no pagaba» (Juan Antonio).

Freeman (1991) calificó estas prácticas como formas de "colectivismo agrario» siguiendo a Joaquín Costa, sistemas altamente redistributivos de carácter local.

Asimismo, Martínez (2014) dice que los bienes comunales han contribuido al igualitarismo y a mitigar la pobreza, y han favorecido la cooperación. De manera que estos valores compartidos por la comunidad suponen que la supervivencia está mejor asegurada y el bienestar aumenta.

Méndez $(2015,31)$ sugiere que gran parte del planeta «depende todavía para su subsistencia de recursos comunes no incorporados al mercado», lo cual genera un interés creciente por los comunes en un momento de descomposición de las instituciones del Estado de Bienestar y de privatización y financiación general de la vida.

Y Alonso y Piñeiro (2015) también se refiere a la actualidad de los comunes, debido a la crisis de la lógica individualista, mercantil y financiera dominante, así como de las "formas burocráticas de los bienes públicos estatales» y sobre sus gestores. De ahí el interés por formas comunales presentes desde la sociedad tradicional, que pueden ser relacionadas con lo colaborativo y coo- 
perativo, tan en boga actualmente. En el mismo sentido, Sabin $(2015,37)$ propone recuperar el concepto de lo común en «el presente momento de expolio y destrucción de recursos e instituciones que garantizan el bienestar y la reproducción social», puesto que los comunes favorecen la vida comunitaria.

En todo caso, este carácter social y comunitario de los bienes comunales favoreció un entramado de aldeas, de formas de cultivo y de sentido colectivista en los agricultores del pasado. El aprovechamiento privado de los bienes comunes iba parejo al acceso y uso comunal a las fincas particulares, con la figura de la «derrota de mieses», que permitía a los vecinos acceder a las tierras de particulares tras la recolección del fruto, espigando en los rastrojos y utilizándolos de pasto para los rebaños de ovejas.

Martín $(1990,30)$ se ha referido a la figura de la derrota de mieses enfatizado que implica la "pérdida del carácter privado de la tierra durante un espacio de tiempo" y una cierta racionalidad en el acceso y uso de la tierra (cultivos y pastos), al acotar determinados espacios en épocas de abundancia y abrirlos en tiempos de escasez.

En Torreandaluz, como en otros lugares, para evitar que se agotasen recursos comunales, como la dehesa boyal, existían restricciones durante determinados períodos en los cuales no podía llevarse a los animales a la dehesa, para que esta se reprodujera adecuadamente. Eran estrategias de gestión comunitaria procuraban evitar el agotamiento de los recursos, pues los lugareños eran conocedores de los límites de los mismos y de su posible empobrecimiento. Es posible pensar que, conocedores de la posible tragedia, los ganaderos limitaban el tamaño de sus rebaños a la capacidad de los bienes comunes y a la del aprovechamiento de sus respectivas propiedades:

\footnotetext{
«Las ovejas no se llevaban a la dehesa, cada uno guardaba las suyas. La dehesa ya no tenía pasto en verano y por eso se acotaba una parte de los rastrojos. El coto estaba en la tierra buena, de particulares. Y no se podía entrar, los ganaderos pagaban estos pastos, por escote de las hectáreas de tierra que había. La dehesa se abandonó cuando ya no había ganado mayor para guardar, cuando había, las ovejas no se metían pues te podían denunciar y además la pradera no es comida buena para las ovejas, sí para el vacuno, pero lo que come el vacuno, en sí, para la oveja no vale» (Juan Antonio).
}

Por lo tanto, el acceso a las dehesas queda regulado por las Ordenanzas municipales que regulan la gestión de su uso. Según Martínez (2014), cada comunidad tiene sus normas que pretenden adaptarse a las necesidades locales, a pesar de los intentos globalizadores y centralizadores que a finales de la Edad Media intenta el poder central, por lo que no existe un modelo unifor- 
me, ya que los municipios castellanos se resistieron a estos intentos uniformizadores. Las Ordenanzas regulaban todos los aspectos económicos y sociales de las dehesas.

Hay más ejemplos en otros lares. Viola (1993), refiriéndose a la organización comunal de los Andes, defiende que es una estrategia adaptativa eficaz, más que una ideología o una costumbre caduca, puesto que la gestión de recursos comunales se dirige a la gestión de aquellos recursos cuya gestión individual sería ruinosa. Así pues, en los Andes se da un continuum entre usos privados y comunales de la tierra, de lo cual, según él, las familias obtienen mayores beneficios.

Roigé, Beltrán y Estrada (1993), refiriéndose a la Vall d'Aran (Lleida), plantean que el aprovechamiento de los distintos estratos ecológicos, se complementaba con la coexistencia de aprovechamientos comunales y privados, pues una y otra forma de apropiación se realizaba sobre espacios productivos distintos. La propiedad comunal era sobre el bosque y los pastos de alta montaña.

\section{AGRICULTORES Y GANADEROS: MÁS COLABORACIÓN QUE ENFREN- TAMIENTO}

La relación entre agricultores y ganaderos no ha sido siempre plácida, e implica roces, enfrentamientos y colaboraciones. En Torreandaluz ha predominado la colaboración, puesto que el tipo de ganadería que se practicaba era complementario a la agricultura, siendo propietarios de ganado la mayoría de los agricultores, y haciendo prácticas de barbecho y de aprovechamiento de pastos y restos de la cosecha, así como de estercolado de los campos.

Convenimos con Doménech (1994) en que la trashumancia en España respondía a la adaptación a las condiciones agroclimáticas del país, y que la Mesta consiguió importantes privilegios desde el siglo XIII, hasta que el ovino perdió importancia económica por la caída del precio de la lana y su sustitución como parte del desarrollo de Castilla por los cultivos de cereal en el siglo XIX. Según este autor, desde principios del XIX, con las primeras pérdidas de privilegios de la Mesta, se definen nuevos modelos agrícolas y ganaderos, que se desarrollarán durante el siglo XX. Hasta entonces en España, el sector ganadero tenía mayor peso respecto el sector agrícola (en relación a Europa), iniciándose una evolución diferente, siendo hoy la situación inversa. Esto, en España, contribuyó a agravar el enfrentamiento histórico agrícola-ganadero, por lo que se consolidó un modelo ganadero extensivo, que 
aprovechaba las peores tierras. Al perder valor la lana, la producción se dirigió a la leche y la carne:

\begin{abstract}
«De unos cuarenta agricultores, veintiocho tenían ganado, pero el maestro y, por ejemplo, el cabrero, no tenían. Era mejor tener ganado y agricultura que solo ser agricultor. "Un agricultor sin ovejas, antes sin orejas", se decía. Pues combinar las dos cosas era mejor, y el que tenía solo tierra marchaba peor que el que tenía las dos cosas. Se autoabastecían. Se tenían corderos que se podían matar para comer cuando se quería, luego se tenía dos cabras para leche, y con eso ibas bastante apañado» (Juan Antonio).
\end{abstract}

Anes (1999) describe que, por el carácter de la actividad agrícola, surgen pocas innovaciones técnicas entre los siglos XVI y XVIII, basándose en el uso de animales para las labores agrícolas. Describe una sociedad de labriegos, que a la vez ejercen de ganaderos y de artesanos, para procurarse gran parte de lo necesario para la subsistencia. Las familias colaboraban en distintas tareas y sus miembros participaban de muchas de las actividades. Describe la utilización de ovejas, cabras y vacas para emplear los residuos agrícolas, limpiar los campos y aprovechar tierras no dedicadas a la labor. El modelo producía un cierto estancamiento poblacional puesto que la supervivencia dependía del volumen de las cosechas, subordinada al rendimiento de la tierra y de los cambios climáticos. Una mala cosecha incrementaba enfermedades y mortalidad.

Subraya la actitud conservadora de la gente del campo que llevaba a hacer las cosas y tareas según la transmisión oral recibida, con pocos cambios, fruto de la experimentación, pero lentos. Pero, como bien señala, cabía la posibilidad de la roturación de nuevas tierras para producir más cereales o alimentar a más ganado, y surgieron discusiones en torno a los privilegios de la Mesta que podían invadir sembrados y rastrojeras, en el ir y venir, lo que volvía indefinibles los derechos de propiedad de los labradores. Pero a medida que en el siglo XVIII aumentaba la extensión de tierra sembrada disminuía la superficie de pastos, también por el hecho de roturar tierras que antes proporcionaban permanentemente hierbas, aunque se compensaba con los rastrojos y los eriazos y paja obtenida en cada cosecha, lo cual conllevó problemas para la trashumancia. De ahí que los ilustrados se plantearan la ley que en Portugal prohibía tener ganado si no se era labrador, y algunos de ellos creían que la despoblación de España se debía a la Mesta. La queja venía por las dehesas y pastizales que no se dedicaban al cultivo, y por los privilegios de la Mesta. Por ello, los ilustrados promovieron los cercamientos de las propiedades para evitar la entrada del ganado ajeno. 
También señala la costumbre del sistema de hojas para alternar la siembra; rastrojo, eriazo y barbechos (en cultivos al tercio o más años), o siembra, rastrojo y barbecho, en el caso de cultivo año y vez (Anes, 1999). Esta disposición tan antigua, llevaba a asociar ganado y labranza, pues era la forma más eficaz de organizar el terrazgo y el cultivo, abonando las hazas el ganado mientras aprovechaban los pastos:

«Antes de los años 60 la tierra se trabajaba por el sistema de año y vez. Cada año se trabajaba una parte de término del pueblo, lo que se denominaba añadas, y la otra parte del término permanecía de barbecho. En las parcelas que se sembraban se producía trigo, cebada y centeno, principalmente. Las fincas eran pequeñas, no había concentración parcelaria. Luego en las de barbecho se sembraban leguminosas: titos, guijas, garbanzos y alubias en algún corro; patatas en lo más bueno. Y luego en lo que se había sembrado de leguminosas, al año siguiente, iba sembrado el cereal. Por eso se hacían las añadas y así poder pastar en el barbecho, de forma libre, se podía pasar por cualquier sitio. El ganado se mantenía con lo que comía en los barbechos, vigilando de no meterlas en las leguminosas, y de los cerros que no se sembraban» (Juan Antonio).

«Las añadas se hacían para favorecer mantener el ganado. Cuando se hizo la concentración en 1964 desaparecieron las añadas, cada cual sembraba cuando quería sin guardar un orden, pues podía pasar que en un lado de la añada alguien no tuviera parcelas y se cambió el sistema. Aunque se mantuvo la libertad para entrar en los rastrojos y barbechos aunque no se fuera propietario de ellos, no había más que respetar los cultivos» (Juan Antonio).

Domenech (1994) ratifica que el sector ovino es diferente en cada zona española en función del entorno y clima. Los pastos son la fuente principal de alimentación, obligando al pastoreo diario, y la adaptación a las condiciones climáticas y la estacionalidad de los pastos. Cuando disminuye el pasto, se hace trashumancia, trasterminancia o se complementa en pesebre el pastoreo (lo que encarece el producto):

«Luego cuando vinieron los compuestos, pues ya venía la comida preparada, pero lo más sano e ideal es la hierba del campo y el pienso natural. La hierba del campo es la que lleva mejor composición. La oveja aprovecha todo, los cerros, lo que sea, lo que las vacas no comerían. Aplica todo lo que hay. Antes llovía más y el pasto duraba hasta julio, luego se agostaba, y aunque hubiera pasto al agostarse se secaba y la oveja aunque comiera, perdía, el pasto debe estar verde sino no tiene alimento» (Juan Antonio).

El cultivo por hojas permite que gracias a las estrategias de barbecho obligatorio, el territorio se divida en «hojas de cultivo» y, como señala Martín 
Galindo (1987) en su análisis de la propiedad comunal de los pueblos de León, la agricultura "descansaba sobre el barbecho bienal obligatorio, es decir que todas las tierras sembradas estaban juntas y las que descansaban estaban igualmente agrupadas en un segundo pago que era aprovechado por las ovejas» (Martín Galindo, 1987, 85). Este tipo de rotación bienal favorecía el aprovechamiento ganadero de los barbechos, pues al no estar mezcladas o intercaladas las parcelas cultivadas y las de barbecho, se podía pastar sin preocupación excesiva en los barbechos:

«La mitad del término estaba de barbecho. Habíamos calculado la mitad del término, de un arroyo a otro, o desde la carretera, todo el término en dos partes, una de barbecho y otra de cereal. Las añadas se hacían para favorecer el guardar las ovejas y cabras. Donde estaba el trigo, en marzo o abril se vedaba, ya no podía ir el ganado, tenía que estar en el barbecho. Se vedaba porque en el pueblo había veintiocho ganados, e iba gente joven con el ganado, y hacían daños pues el ganado se comía lo que no debía, los trigos» (Juan Antonio).

\section{LA POBLACIÓN: EL ABANDONO DE LOS PUEBLOS}

Según Bachiller (1996, 31), entre 1900 y 1995 la población del suroeste soriano se redujo a menos de la mitad, siendo la caída más importante entre 1950 y 1981, especialmente entre 1960 y 1975 (37\%).

Bachiller (1996) plantea que el éxodo rural de los años 60 y 70 fue un éxodo fuera de la comarca y de la provincia, puesto que las cabeceras de comarca (Almazán, el Burgo de Osma y San Esteban de Gormaz) no retuvieron a los migrantes de los pueblos de la zona, que no sólo cambiaron de lugar de residencia sino también de actividad.

Emigraron principalmente a Cataluña, Madrid y País Vasco, especialmente los jóvenes, y más mujeres que hombres. Según Bachiller (1996), en los pueblos, aunque ha mejorado el nivel económico y las condiciones de vida, se ha empeorado el nivel social, haciendo inviable la continuidad de los pueblos pequeños que no cuentan con los servicios necesarios para el tipo de vida actual. Por lo que, aunque las personas adultas estén adaptadas a este tipo de vida, los jóvenes optan por seguir con las labores, pero sin residir en los pueblos, que se van abandonando, puesto que la emigración anterior ya los dejó sin jóvenes y no hubo reposición de población. Como bien señala el autor, el entramado de pueblos de esta zona del suroeste soriano, de pueblos minúsculos y dispersos, estaba adaptado a un sistema económico feudal y choca ahora con el mundo globalizado y urbano. 
La mecanización del campo favorecida por la concentración parcelaria de los años sesenta y setenta; la incorporación de nuevas simientes, fertilizantes y pesticidas; la roturación de nuevas tierras y por tanto la extensión de la tierra de cultivo; así como el abandono y migración a otros lugares de muchos agricultores y ganaderos, hicieron posible el modelo agrícola naciente en los años sesenta. Y, aunque según Ruiz (2001), Soria siempre tardó en incorporarse a los cambios tecnológicos del campo, desde los años sesenta ha acelerado el proceso de mecanización del campo y de expulsión de población de los pueblos, hasta los mínimos actuales:

\begin{abstract}
«Cuando llegaron los tractores la gente empezó a labrar un poco más y si las ovejas no les gustaban pues se retiraban. La gente empezó a coger tierras en renta y a sacarse las ovejas, se llegaba a juntar unas ochenta hectáreas, pues es cuando empieza a emigrar gente que dejaban la tierra. Se juntó el tractor con que emigraba la gente, pues si en una casa había tres hermanos pues dos emigraban, las ovejas se eliminaban y el que quedaba, con el tractor, defendía lo que hacían los tres» (Juan Antonio).
\end{abstract}

La Revolución Verde ha afectado la zona y el balance puede verse desde ópticas diferentes. Ha aumentado la superficie sembrada, los rendimientos por hectárea, el nivel de mecanización de los agricultores; y ha disminuido considerablemente el barbecho, así como el número de agricultores y ganaderos. Se ha acentuado la dependencia económica del mercado global, ha pasado a ser de las zonas más despobladas, se requiere cada vez más fertilizantes y herbicidas para el monocultivo cerealista. El impacto ecológico ha sido brutal y negativo, y empiezan a verse rendimientos decrecientes de las parcelas más pobres que hace que algunas de ellas serán inviables, en breve tiempo, con el sistema actual de cultivo:

«Entonces de una hectárea de trigo se sacaba como mucho unos $2.000 \mathrm{~kg}$, pero claro antes de la concentración no sabíamos ni el número de hectáreas que teníamos. Pero sabíamos que daba a tantas simientes, más o menos de ocho a diez simientes. A mano quizás se sembraba más espeso. Hoy se siembra sobre $200 \mathrm{~kg} / \mathrm{ha}$. La cebada y el trigo se aproximaba, la avena salía menos y el centeno salía todavía menos, igual sobre $1000 \mathrm{~kg} / \mathrm{ha}$, pero como que no había gastos, dejaba dinero. Hoy las tierras rinden más o menos, pero se gasta más, y además los precios, lo que compramos se ha multiplicado y lo que vendemos se ha quedado igual que hace veinte años, así que, aunque rinda igual... va mucho peor para quedar beneficios. $Y$ encima las tierras están cansadas por no hacer barbecho y rinden menos» (Juan Antonio).

La concentración parcelaria en Torreandaluz, no solo incorporó tierras de baldíos que se roturaron y que por tanto disminuyeron las zonas de pastoreo, 
sino que disminuyó los pastos por la eliminación de la gran cantidad de ciratos y de arroyos:

«Pero antes de venir la concentración, pues entonces se podía llevar más por el barbecho que se hacía y las añadas. Aunque entonces no se tenían tantas. Cuando empecé yo, con cien ovejas el que más, te manejabas bien. Debido a la concentración... Es que la concentración ha sido muy mala para la oveja. Vino también los tractores con la concentración, ya no había añadas, y se labraba mucho más, pues que el pasto se fastidiaba y había quien ya no hacía barbecho y lo sembraba todo, y al ganado lo fastidiaba» (Juan Antonio).

Existe otro hándicap: el nivel de mecanización de los actuales agricultores es muy alto, pero la mayoría de ellos no encuentran nuevas tierras en rentas o para comprar, lo que implica un exceso de mecanización:

"Cuando llegaron los tractores hubo que comprar todos los aperos: vertedera, cultivador pequeño, abonadora, remolque. Unos hacían grupo. Había sulfatadora del pueblo. La Cámara Agraria daba subvenciones a los grupos y a las cooperativas. Los grupos al principio bien, les cambió mucho, labraban más tierra e hicieron dinero, pero en cuanto pasaban diez años que estaban obligados a mantenerlo por las subvenciones de la Cámara, si les iba bien, lo deshacían, cada uno por su cuenta. Pasó en muchos pueblos. Si hasta hermanos que iban juntos, se han apartado, cuando se defendían bien, y se han montado por su cuenta. Ahora cuando se hacen cuatro perras, se separan» (Juan Antonio).

Todo ello, con la actual política de precios de los cereales, nos hace vislumbrar un futuro incierto que llevará a la desaparición de muchos pueblos, y aunque en verano o los fines de semana sus antiguos moradores regresen, Torreandaluz y tantos otros lares dejarán de tener pastores, agricultores, niños y mujeres que residan en el lugar. No se oirán risas ni conversaciones. Una triste historia para las próximas generaciones:

«El tractor, la concentración y luego los herbicidas, otro perjuicio para el ganado, hasta entonces no hacía falta herbicida pues las ovejas lo comían todo, con el ganado que había. Dependía de los pueblos. Pero claro, de guardar era costoso, y al que no le gustaban las ovejas, cuando llegaron los tractores, vendieron las ovejas y cogieron más labor. La oveja era muy necesaria porque si no, del campo, no llegabas. La oveja dejaba en aquellos tiempos tres veces más que la tierra de beneficio, la tierra, fíjate, cuando no se echaba abono, ¿qué se sacaría por hectárea? Pues igual no llegaba a mil kilos, pero es que no se echaba abono y las semillas para criarse eran mejores que ahora, eran más fuertes, porque ahora es muy señorita la semilla, sí, pues ahora no aguantan si no llueve o si hace mucho calor, antes se criaban mejor, y trigos buenos, sí, sin echarles» (Juan Antonio). 


\section{CONCLUSIONES}

Antes de los años setenta unas cuarenta familias vivían de la agricultura y el pastoreo en Torreandaluz, en la actualidad se han reducido a menos de diez, y ninguna de ellas vive permanentemente en el pueblo, aunque la agricultura sea su ocupación principal.

Antes de los años sesenta la mayoría de las familias de agricultores compaginaba las labores del campo con el pastoreo, en la actualidad no existe ninguna cabeza de ovino en Torreandaluz, desaparecieron los rebaños en el cambio de siglo.

El inicio en el pastoreo se realizaba precozmente sobre los nueve o diez años. Lo hacían igual los chicos que las chicas, aunque ellas lo abandonaban antes. En los inicios no se manejaba todo un rebaño sino algún hatajo más pequeño.

Se ha perdido diversidad ecológica puesto que han desaparecido cultivos específicos para el ganado mayor y el ovino. También la dehesa, destinada principalmente al ganado mayor, ha desaparecido como tal y ha sido roturada y sembrada de cereales cada año.

La colaboración que se producía entre agricultura y ganadería ha desaparecido en favor del monocultivo de cereales. El aprovechamiento de pastos y desechos de cosechas mediante el pastoreo se ha perdido con la desaparición de los rebaños.

El uso de los baldíos y comunes favoreció el pastoreo. La desaparición de los ovinos ha favorecido la roturación de tierras que antes se dedicaban a los ganados.

La agricultura que se practica en Torreandaluz desde los años setenta es muy dependiente de los aportes de fertilizantes y herbicidas, y ha contribuido al monocultivo cerealista, generando una creciente dependencia económica del mercado global, viéndose los agricultores sometidos a sus fluctuaciones y cambios.

A pesar del aumento de las aportaciones de abonos y herbicidas, no se produce un crecimiento importante y sostenido de los rendimientos agrícolas.

\section{BIBLIOGRAFÍA}

Aguirre, A. (1991). Algunas notas sobre veterinaria popular. En L. Elías y J. Grande (Coord.), Sobre cultura pastoril. Arnedo: Centro de Investigación y animación etnográfica, 11-28. 
Alonso L. E. y Piñeiro, C. (2015). El procomún y los bienes comunes. En Economistas sin Fronteras, El procomún y los bienes comunes. Dosieres ESF, 16, 4-17.

Anes, G. (1999). Cultivos, cosechas y pastores en la España Moderna. Madrid: Real Academia de la Historia.

Bachiller, J. M. (1996). Espacios rurales desfavorecidos. Las transformaciones del suroeste soriano. Valladolid: Universidad de Valladolid.

Blanco, A. L. (2014). La imprescriptibilidad de los bienes comunales: su trascendencia para la conservación de la propiedad forestal pública”. Revista Jurídica de Castilla y León, 32, 5-37.

Domènech, J. M. (1994). Mil millones de ovejas: Estudio socioeconómico del subsector de ganado ovino en la Rioja, España y el mundo. Logroño: Fundación Rural de la Caja de Ahorros de la Rioja.

Economistas sin Fronteras (2015). El procomún y los bienes comunes. Dosieres EsF, 16.

Freeman, S. T. (1991). Estructuras igualitarias en los sistemas sociales ibéricos: Los contextos de rotación en lo urbano y rural. En J. Prat et al. (Eds.), Antropología de los pueblos de España. Madrid: Taurus Universitaria, 520-539.

Garzón, J. (2012). Importancia de la trashumancia en España para conservar la diversidad biológica en Europa y mitigar el cambio climático. Asociación trashumancia y naturaleza. <http://www.pastos.es/pdf/ ADAPTACIoN\%20AL\%20CAMBIO\%20CLIMaICO\%20MEDIANTE\%20LA\%20TRASHUMANCIA\%2030.01.pdf>.

Goig, I. (2015). Tal y como vivíamos. (De costumbres). Soria: Ochoa Impresores.

Hardin, G. (1968). The Tragedy of the Commons. Sciencie, 162, 1243-1248. Manzano, P. (2004). Aproximación experimental a la dispersión epizoócora a larga distancia por ovejas trashumantes. Madrid: Universidad Autónoma de Madrid. Memoria para la obtención del título de Estudios Avanzados. Martín Galindo, J. L. (1987). Poblamiento y actividad agraria tradicional en León. Valladolid: Junta de Castilla y León.

Martínez Veiga, U. (1993). Evolución de la propiedad comunal, el caso de León. En J. Pascual, Procesos de apropiación y gestión de recursos comunales. Tenerife: FAAEE. Actas del VI Congreso de Antropología, 91-104.

Martínez, L. (2014). La gestión de los recursos comunales y la igualdad en la comunidad de San Andrés de Soria. Barcelona: Universidad de Barcelona. Tesis Doctoral. 
Mato, A. (2010). La Sociedad rural en el Concejo de Ponga (1750-1930): Labradores, pastores, madereros y arrieros. Oviedo: Universidad de Oviedo.

Méndez, A. (2015). «Las formas del común». En Economistas sin Fronteras, El procomún y los bienes comunes. Dosieres ESF, 16, 31-36.

Pérez, R. M. (1993). El derecho de suertes en la zona de pinares de Soria. Boletin de la Facultad de Derecho, 4.

Pérez Romero, E. (1995). Patrimonios comunales, ganadería trashumante y sociedad en la tierra de Soria. Siglos XVIII-XIX. Salamanca: Junta de Castilla y León.

Pérez Romero, E. (2009). Un mundo inmóvil. El producto agrícola por habitante en la cuenca alta del Duero durante la Edad Moderna. Investigaciones de Historia económica. Valladolid: Asociación Española de Historia Económica, 69-102.

Roigé, X., Beltrán, O. y Estrada, F. (1993). Diversidad ecológica y propiedad comunal. El pueblo como organización política, económica y social en el Val d'Aran (Pirineos). En J. Pascual, Procesos de apropiación y gestión de recursos comunales. Tenerife: FAAEE. Actas del VI Congreso de Antropología, 73-90.

Ruiz, E. (2001). Historia económica de Soria. Desde la antigüedad hasta el presente. Soria: Centro de Estudios Sorianos.

Sabin, F. (2015). La economía solidaria, el movimiento cooperativista y los comunes. En Economistas sin Fronteras, El procomún y los bienes comunes. Dosieres ESF, 16, 37-41.

Serna, M. (1993). Estudio histórico-jurídico sobre los bienes comunes. Revista Aragonesa de Administración Pública, 3, 206-229.

Vallejo, A. (2009). En Soria las aldeas se mueren: La Ventosa de Fuentepinilla. Soria: Excma. Diputación.

Viola, A. (1993). Entre el sentimiento y el interés: La gestión comunal de recursos en las comunidades campesinas de los Andes. En J. Pascual, Procesos de apropiación y gestión de recursos comunales. Tenerife: FAAEE. Actas del VI Congreso de Antropología, 47-57. 